\title{
Simultaneous Estimation of Optical Properties of Asian Dust and Ground Reflectance by Polarization Measurements
}

\author{
Takashi Kusaka and Ryuichi Taniguchi \\ Kanazawa Institute of Technology
}

\section{Introduction}

The Asian dust transported from desert areas in the northern China often covers over East Asia in the late winter and spring seasons. It is regarded as a main source of atmospheric aerosols over East Asia and has significant effects on the climate change. Moreover, fine dust particles in the air have harmful influence on our health on the local and global scales. However, it is as yet very difficult to extract optical properties of the widely spread hazy dust from satellite data over land surfaces because the radiance received by a satellite sensor strongly depends on the surface reflectance. It will be, therefore, necessary to estimate optical properties of the Asian dust and the ground reflectance simultaneously from satellite data. In particular, the polarimetric information will provide the improvement of estimating optical properties of atmospheric aerosols.

Many authors have investigated dust properties over ocean (Nakajima et al.,1998, Tanre et al.,1997) and over dark vegetated areas (Kaufman et al.,1997a, Kaufman et al.,1997b) using satellite measurements. In these cases, the surface contribution to the radiance received by the satellite sensor is small. However, the linear polarization is less commonly measured than the radiance in the remote sensing at optical and near infrared wavelengths.

The ADEOSII/POLDER and PARASOL/POLDER observe the reflectance and polarization of a target quasi-simultaneously in multi-viewing angles at wavelengths of $443 \mathrm{~nm}$ (ADEOSII/POLDER), 490nm (PARASOL/POLDER), 670nm and $865 \mathrm{~nm}$, and so POLDER data provide enough information to determine optical characteristics of atmospheric aerosols and the ground reflectance. We have developed the algorithm for estimating optical properties of dust particles and the surface reflectance simultaneously from POLDER data (Kusaka et al., 2001, 2002b, 2004). However, absorption of light ray by dust particles is not taken into account in the estimation algorithm.

In order to investigate the usefulness of the polarization for aerosol particles, we have made ground-based polarization measurements of the sky radiation by the PSR-1000 (Masuda,1997), which is the multi-spectral polarimeter produced by Opt Research Corporation, Japan and has the same wavelength regions $(443 \mathrm{~nm}, 490 \mathrm{~nm}, 565 \mathrm{~nm}, 670 \mathrm{~nm}$, $765 \mathrm{~nm}$ and $865 \mathrm{~nm}$ ) as the POLDER sensor. In the following sections, we will describe the results of ground-based polarization measurements and a new algorithm for estimating 
aerosol properties over land using the polarized radiance received by the POLDER. In this new algorithm, absorption of light by aerosols will be taken into account.

\section{Ground-based polarization measurements}

The vertical profiles and optical properties of aerosols including Asian dust have been investigated by means of Lidar observation (NIES, Japan) and sun photometer measurements (AERONET, NASA) from ground stations. However, ground based polarization measurements are as yet very sparse.

We have made polarimetric measurements of the sky radiation at the ground station in the Kanazawa city, Japan, which is located at the side of the Sea of Japan, in the spring season from 2000. Asian dust clouds often appear together with normal clouds, and so we have only measured the degree of polarization of the sky light when the Kanazawa city was covered with a thin dust cloud.

\subsection{Description of PSR-1000}

The PSR-1000 measures the intensity of the sky radiation. A Glan-Thompson prism is implemented between the hood ( 2 degrees field of view) and the interference filters in the PSR-1000 instrument. The prism rotates automatically by a pulse motor and the range of the rotation is 0 to 360 degrees. The measurement by the PSR-1000 is controlled by a personal computer (PC). The optical instrument attached on the tripod is pointed manually to a desired direction to measure the intensity of the sky radiation. Since the received signals change sinusoidally against the angle of rotation of the polarizer (Hansen, et al., 1974), the maximum signal value, $I_{\max }$ and the minimum value, $I_{\min }$ can be easily obtained from the sinusoidal curve. The degree of linear polarization, $\mathrm{L}$, is therefore given by

$$
\mathrm{L}=\left(\left(\mathrm{I}_{\max }-\mathrm{I}_{\mathrm{dk}}\right)-\left(\mathrm{I}_{\min }-\mathrm{I}_{\mathrm{dk}}\right)\right) /\left(\left(\mathrm{I}_{\max }-\mathrm{I}_{\mathrm{dk}}\right)+\left(\mathrm{I}_{\min }-\mathrm{I}_{\mathrm{dk}}\right)\right)
$$

where $I_{d k}$ is the dark signal that is the signal received in no incident solar radiation. As seen from Eq.(1), no absolute calibration of the optical instrument is needed in the polarization measurement because the degree of polarization is the relative value.

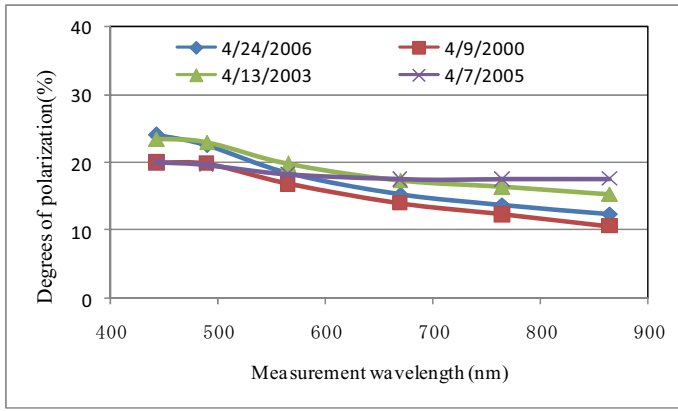

Fig. 1. Degrees of polarization measured at the angle of 90 degrees from the solar direction when Kanazawa city was covered with Asian dust 


\subsection{Polarization measurements of the sky radiation}

Polarizations were measured at angles of 90 and 120 degrees from the solar direction in the principal plane in 2000 to 2002. From 2003, polarization measurements were carried out at angles of 75, 90, 105 and 120 degrees from the solar direction in the principal plane.

Figure 1 shows degrees of polarization measured at the angle of $90^{\circ}$ from the solar direction when the hazy dust was recognized at the meteorological observatory in the Kanazawa city. Figure 2 shows degrees of polarization measured at the angle of $90^{\circ}$ from the solar direction in the clear sky. Figure 3 shows angular dependencies of polarization at $490 \mathrm{~nm}$ measured on April 13 and 27, 2003. As seen from Figure 1 to Figure 3, degrees of polarization measured in the sky covered with the hazy dust decrease uniformly as the wavelength increases and are lower than those in the clear sky. The wavelength dependencies are slightly different in the measurement date. In particular, most of degrees of polarization measured in the clear sky show the peak value around the $490 \mathrm{~nm}$ channel. In polarization measurements in the clear sky, we have often similar polarization patterns as measured on April 27, 2003. In this case, we pointed out that this will be due to light scattering by small aerosols included in the atmosphere (Kusaka, et al., 2002a).

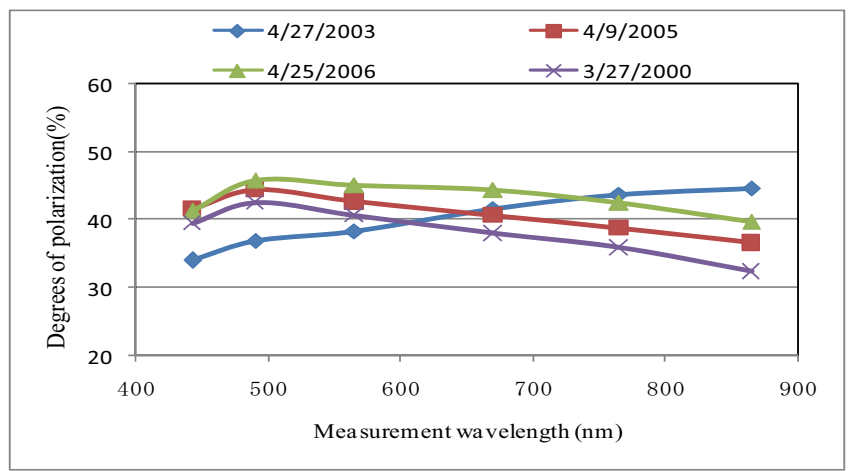

Fig. 2. Degrees of polarization measured at the angle of 90 degrees from the solar direction in the clear sky

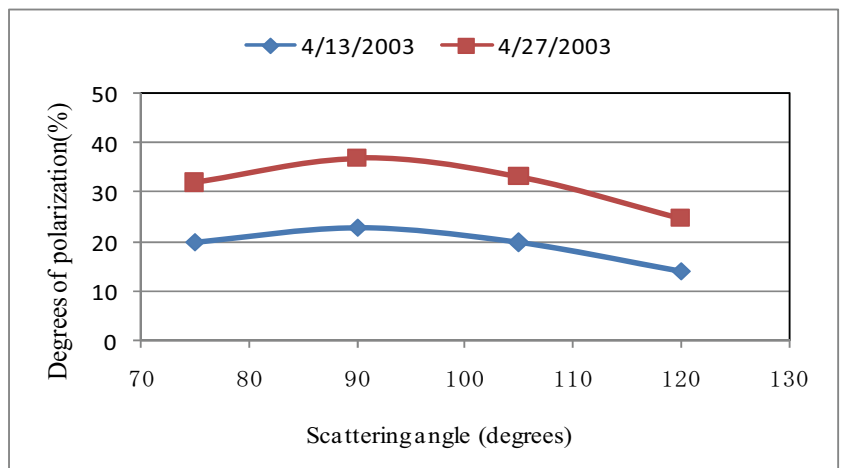

Fig. 3. Degrees of polarization at 490nm measured at angles of 75, 90, 115 and 120 degrees from the solar direction on April 13 and April 27, 2003 


\section{Estimation of dust properties and surface reflectance}

A basic idea for estimating optical properties of aerosols and the surface reflectance is very simple, and aerosol properties and surface reflectance are estimated, by comparing the radiance and polarization obtained from satellite and ground-based measurements with those obtained from the computation of multiple scattered light in the atmosphere-ground system.

The radiance and polarization of scattering light are completely described by the Stokes parameters ( $\mathrm{I}, \mathrm{Q}, \mathrm{U}, \mathrm{V})$, where $\mathrm{I}$ is the radiance and the other parameters have same dimension. We have $\mathrm{V}=0$ in the linear polarization. The linearly polarized radiance Ip and the polarization direction $\chi$ can be derived from $Q$ and $U$ as follows (Hansen, et al., 1974):

$$
\begin{aligned}
I_{p}=\sqrt{Q^{2}+U^{2}} \\
\\
\quad \tan (2 \chi)=U / Q
\end{aligned}
$$

The degree of polarization is defined as the ratio Ip/I.

\subsection{Estimation of aerosol properties by ground-based polarization measurements}

We estimate optical properties of aerosols using degrees of polarization of sky light measured at four scattering angles by the PSR-1000. To do that, we computed degrees of polarization at the bottom of the atmosphere in the plane parallel uniform atmosphere bounded by the uniform background surface by means of the Monte Carlo integration (O'Brien, 1998, Ishimoto, et al., 2002). In the radiative transfer simulation, it was assumed that the number size distribution of aerosols is represented by the Junge power-law (radius $\mathrm{r}<0.1 \mu \mathrm{m} \mathrm{dN} / \mathrm{dr}=$ const., $\mathrm{r}>0.1 \mu \mathrm{m} \mathrm{dN} / \mathrm{dr}=\mathrm{cr}^{-\mathrm{a}}$, minimum radius: $0.05 \mu \mathrm{m}$, maximum radius: $15 \mu \mathrm{m})$ and the dust particle is spherical, non-absorption matter. Moreover, we assumed that the land surface is the uniform Lambertian reflector.

Therefore, parameters to be estimated from the measured polarizations are the optical thickness of aerosols, $t$, exponent of Junge power-law, a, refractive index of aerosols, $\mathrm{Nr}$, and the background reflectance, A. We determined the values of $t, a, N r$ and $\mathrm{A}$, using the following algorithm:

(1) Degrees of polarizations at the bottom of the atmosphere were computed for typical values of $\mathrm{t}, \mathrm{Nr}$, a, and A and were saved in the Lookup table (LUT) for the solar zenith angle at the measurement time. In this case, only degrees of polarization at angles of 75, 90, 105 and 120 degrees from the solar direction in the principal plane were computed.

(2) We used LUT to determine the values of $t, \mathrm{Nr}$, a and A such that the sum of the square errors, $Q$, between the measured polarizations and the computed ones in four directions is minimum. In this case, the interpolation scheme by the 3rd order polynomials was adopted to obtain the minimum value of $Q$.

We used only degrees of polarization at the $490 \mathrm{~nm}$ channel to estimate values of $\mathrm{t}, \mathrm{Nr}$, a, and A because the radiance received at the bottom of the atmosphere not so much strongly depends on the ground reflectance of the suburban area at $490 \mathrm{~nm}$.

The method described above was applied to degrees of polarization measured on April 13 and 27, 2003 as shown in Figure 3 (kusaka et al., 2007). As a result, we had optical thickness of aerosols $\mathrm{t}=0.8$, refractive index $\mathrm{Nr}=1.62$, exponent of Junge power-law $\mathrm{a}=4.69$ and 
background reflectance $\mathrm{A}=0.0$ on April 13,2003 , and $\mathrm{t}=0.5, \mathrm{Nr}=1.48, \mathrm{a}=4.59$ and $\mathrm{A}=0.024$ on April 27, 2003. We used the estimated values of 4 parameters to compute degrees of polarization at the bottom of the atmosphere. The computed degrees of polarization and the measured ones are shown in Figure 4.

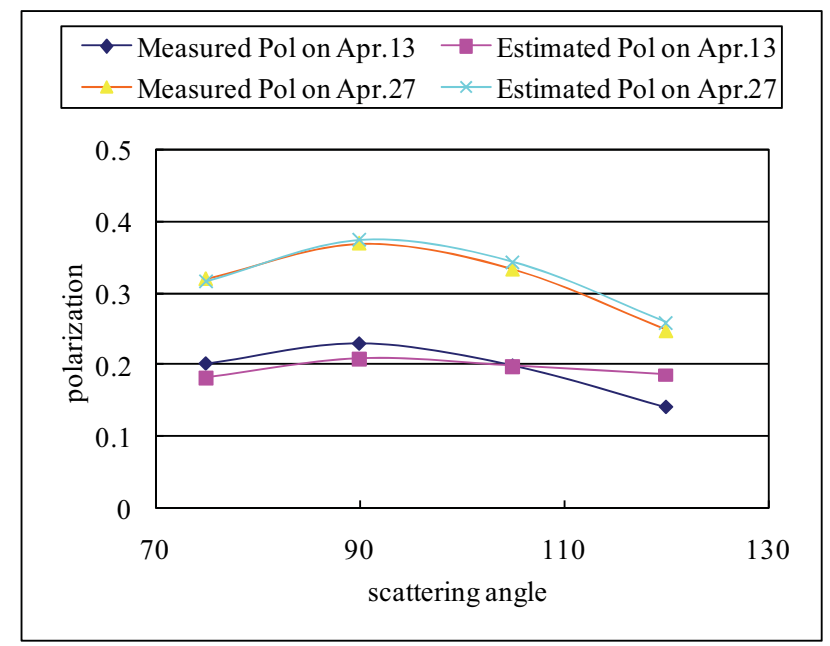

Fig. 4. The estimated degrees of polarization and the measured ones at $490 \mathrm{~nm}$ are shown in cases of April 13 and 27, 2003

As seen from Figure 4, the computed polarizations are very close to the measured ones on April 27 when the optical thickness of aerosols is thin, but on April 13 when the optical thickness of aerosols is thick, the computed polarizations are significantly different from the measured ones. On April 13 and 27, 2003, the aerosol measurement by the sun photometer and the polarization measurement by the PSR-1000 were carried out at the almost same time. The optical thickness of aerosols at the $500 \mathrm{~nm}$ channel by the sun photometer was 0.85 on April 13, and 0.45 on April 27. The estimated optical thickness of aerosols at the 490nm channel was 0.8 on April 13 and 0.5 on April 27. The difference between the estimated value and the measured one is small on April 13 and 27. However, on April 13, the estimated degrees of polarization are significantly different from the measured ones at $490 \mathrm{~nm}$. Therefore, we may need the improvement of the estimation process in the case of the thick Asian dust.

\subsection{Estimation of aerosol properties and surface reflectance by POLDER data}

Kusaka, et al. (Kusaka, et al. 2001, 2002b, 2004) proposed a method for estimating optical properties of Asian dust and the surface reflectance simultaneously from the radiance and polarization observed at each of $443 \mathrm{P}$ and 670P channels of the ADEOS\&ADEOSII /POLDER sensor. It was shown that the method developed by Kusaka, et al. provides reasonable surface reflectance and dust properties such as the optical thickness, the refractive index, the number size distribution of dust particles at the $670 \mathrm{~nm}$ channel. However, at the $443 \mathrm{~nm}$ channel, absorption of light ray by dust particles is not taken into account in the algorithm of Kusaka, et al. Therefore, we will need to have a new method for estimating dust properties more accurately at shorter wavelengths. 
In this section, we describe a new method for the estimation of aerosol properties using the polarized radiance effectively and apply this method to PARASOL/POLDER data.

Since the ground resolution of a POLDER-measured pixel is $6 \times 7 \mathrm{~km} 2$ at nadir, the radiance and polarization at the top of the atmosphere were obtained from the numerical computation of the radiative transfer equation in a uniform plane parallel atmosphere bounded by the uniform Lambertian reflector. We used the 6SV-1.0B code developed by Vermote et al. (Vermote et al. 2006) to compute values of Stokes parameters at the top of atmosphere. In this case, it was assumed that the number size distribution of aerosols is represented by the Junge power-law and aerosol particles are spherical.

By comparing the radiance and polarization received by the POLDER with those obtained from the radiative transfer simulation, we estimate the optical thickness of aerosols, $t$, the exponent of Junge power-law, a, the complex refractive index, $\mathrm{Nr}$ (real part) and $\mathrm{Ni}$ (imaginary part), and the surface reflectance, A.

The optical thickness of aerosols in the near infrared wavelength is generally thinner than that in optical wavelengths and the contribution of light scattering by aerosols to the radiance in the near infrared wavelength received by the satellite sensor is relatively small. In the present study, the retrieval of aerosol properties and the surface reflectance from POLDER data acquired at optical channels will be taken into account.

It is also shown that the contribution of light reflected by the uniform Lambertian reflector to the polarized radiance is very small because the reflected light by the Lambertian surface is depolarized. We investigated the dependency of polarized radiance on the surface reflectance. Figure 5 shows the polarized radiance nomalized by $\cos (\theta \mathrm{s}) \mathrm{E} / \Pi$ against the surface reflectance at $490 \mathrm{~nm}$ and $670 \mathrm{~nm}$ channels, where $\theta \mathrm{s}$ is the solar zenith angle and $\mathrm{E}$ the solar flux at the top of atmosphere. In Figure 5, polarized radiances were computed under the following conditions:

optical properties of aerosols: $\mathrm{t}(550)=0.4, \mathrm{a}=4.0, \mathrm{Nr}=1.5$ and $\mathrm{Ni}=0.0$.

geomeric conditions: solar zenith angle 35 degrees, viewing zenith angle 30 degrees, relative azimuth angle 180 degrees.

atmospheric model: midlatitude winter model.

We can see from Figure 5 that the polarized radiance received by the satellite sensor is independent of the surface reflectance. This indicates that aerosol properties are extracted from polarized radiances received by the satellite sensor.

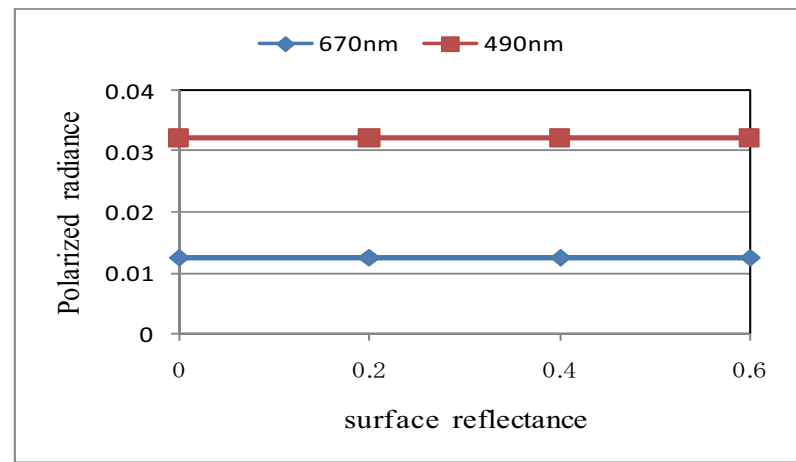

Fig. 5. The dependency of polarized radiances on the surface reflectance at $490 \mathrm{~nm}$ and $670 \mathrm{~nm}$ channels. It is assumed that the ground surface is the Lambertian reflector. 


\subsubsection{Estimation Algorithm at the $670 \mathrm{~nm}$ channel}

(1) Estimation of aerosol properties

Absorption of optical light by dust particles decreases as the wavelength is longer. In this study, we assume that there is very little absorption for dust particles at $670 \mathrm{~nm}$, because we have not so much experimental results for it. Therefore, it is assumed that the imaginary part of complex refractive index, $\mathrm{Ni}$, is zero at $670 \mathrm{~nm}$.

The polarization ( $Q$ and $U$ of Stokes parameters) at a target pixel measured by the POLDER change at geometric conditions of the satellite sensor. We create the look-up table, LUT, for the polarization to retreive the necessary information easily from it. Using the $6 \mathrm{SV}-1.0 \mathrm{~b}$ code, we computed in advance the radiance RAD and the polarized radiance POL and the polarization direction PD at the top of atmospher as the function of the optical thickness of aerosols at 550nm, $t(550)$, refractive index of aerosols, $\mathrm{Nr}$, and index of Junge power-law, a under a given geomeric condition such as solar zenith angle, SZA, viewing zenith angle, VZA, and relative azimuth angle, RAZ. In this computation, the midlatitude winter model given in the $6 \mathrm{SV}-1.0 \mathrm{~B}$ code was adopted as the atmospheric model and the surface reflectance $A$ was taken as 0 . The values of RAD, POL and PD computed for typical values of $\mathrm{t}(550), \mathrm{Nr}, \mathrm{a}, \mathrm{SZA}, \mathrm{VZA}$ and RAZ were saved in the look-up table, LUT.

The Stokes parameters I, Q, U in different viewing conditions at each pixel of POLDER data are computed. Consider that the observed Stokes parameters in different $\mathrm{N}$ geometrical conditions, each of which consists of a 3-tuple of (SZA, VZA, RAZ), were extracted from POLDER data at a target pixel, and polarized radiances POL were computed by Eq. (2). The values of POL against all combinations of $\mathrm{Nr}$, a and $t(550)$ given in LUT were interpolated in all of viewing conditions, $(\mathrm{SZA}, \mathrm{VZA}, \mathrm{RAZ})_{\mathrm{i}},(\mathrm{i}=1, \ldots, \mathrm{N})$. In this case, we adopted the Lagrange 2nd-order polynomials as the interpolation function. The values of $\mathrm{POL}_{\mathrm{i}}$ in the $\mathrm{i}$-th

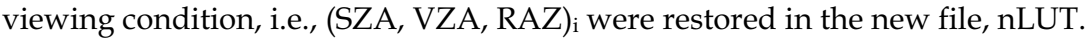

We use the least square method to estimate optimum values of $\mathrm{Nr}$, a ant $t(550)$. Let the polarized radiance observed by the POLDER in a viewing condition, (SZA, VZA, RAZ), be OPL. The sum of square errors between the observed values and the computed ones, $Q$, is defined as

$$
\mathrm{Q}=\sum_{\mathrm{i}=1}^{\mathrm{n}}\left(\mathrm{OPL}_{\mathrm{i}}-\mathrm{POL}_{\mathrm{i}}\right)^{2}
$$

where i represents the i-th geometric condition.

It is necessary to obtain the unique solution that minimizes $\mathrm{Q}$ in the 3-dimensional parameter space. In other words, the problem is to find the values of $\mathrm{Nr}$, a and that correspond to the minimum of $\mathrm{Q}$. In general, the hill climbing algorithm starts by making the initial guess and needs the partial derivatives of a function $Q$ to compute the better solution from the initial solution. In our case, it is difficult to derive the partial derivatives of $\mathrm{Q}$ given by Eq.(4). We also used the modified hill climbing algorithm adopted by Kusaka, et al. (Kusaka, et al., 2004) in which the partial derivatives of $Q$ are not used, to get the minimum of $Q$. The modified hill climbing algorithm provides a local minimum rather than a global one. Therefore, we derived the optimum solution of $\mathrm{Nr}$, a and $\mathrm{t}$ in the following two steps.

Step 1: Using the values of POL stored in the file, nLUT, we compute the values of $Q$ in all combinations of variables $(\mathrm{Nr}, \mathrm{a}, \mathrm{t})$. Then, we can obtain $\mathrm{n}$ values of $\mathrm{Nr}_{\mathrm{k}}$, $\mathrm{a}_{\mathrm{k}}$ and $\mathrm{t}_{\mathrm{k}}$ that 
correspond to $\mathrm{Q}_{\mathrm{k}}\left(\mathrm{Q}_{1}<\mathrm{Q}_{2}<\cdots<\mathrm{Q}_{\mathrm{n}}, \mathrm{k}=1,2 \cdots \mathrm{n}\right)$. The values of $\mathrm{Nr}_{\mathrm{k}}$, $\mathrm{a}_{\mathrm{k}}$ and $\mathrm{t}_{\mathrm{k}}$ are used as initial values. In practical applications, we chose $n=3$.

Step 2: The values of $\mathrm{Nr}_{\mathrm{k}}, \mathrm{a}_{\mathrm{k}}$ and $\mathrm{t}_{\mathrm{k}}(\mathrm{k}=1)$ are first applied to the modified hill climbing algorithm and the new solution $(\mathrm{Nr}(1), a(1), t(1))$ corresponding to the new local minimum $Q(1)$ is obtained. This procedure is repeated for $n$ initial values. As a result of it, we have $n$ values of 3 parameters corresponding to local minimum values $Q(1), \ldots, Q(n)$. As the optimum solution, we choose $\mathrm{Nr}(\mathrm{j})$, $a(j)$ and $t(j)$, corresponding to the minimum value, $Q(j)$, among $Q(1), \ldots, Q(n)$, where $j$ is one of $1,2, \ldots n$.

\section{(2) Estimation of surface reflectance}

Since optical properties of aerosols such as $\mathrm{Nr}$, a, and $\mathrm{t}$ were determined in the previous section, we can easily estimate the surface reflectance using the radiance received by the POLDER. First of all, by using the estimated $\mathrm{Nr}$, a and $\mathrm{t}$, the radiance, $\mathrm{CI}$, at the top of atmosphere is computed for a surface reflectance under a given geometric condition received by the POLDER and is compared with the radiance, OI, received by the POLDER.

After computing the values of $\mathrm{CI}$ in typical four surface reflectances, A1, A2, A3 and A4 for all viewing conditions of the POLDER, we determine the surface reflectance in the range of $\mathrm{A} 1$ to $\mathrm{A} 4$ that minimizes the sum, $\mathrm{QR}$, of square errors between the observed radiances and the computed ones. QR is defined as

$$
\mathrm{QR}(\mathrm{A})=\sum_{\mathrm{i}=1}^{\mathrm{n}}\left(\mathrm{OI}_{\mathrm{i}}-\mathrm{CI}_{\mathrm{i}}\right)^{2}
$$

We also used the modified hill climbing algorithm to obtain the surface reflectance, A.

\subsubsection{Estimation algorithm at $490 \mathrm{~nm}$}

In general, the refractive index slightly increases as the wavelength is shorter, but the measurement for the wavelength dependency of dust particles is as yet very sparse. In the present study, we assume that the refractive index, $\mathrm{Nr}$, does not depend on the wavelength and so $\mathrm{Nr}$ at $490 \mathrm{~nm}$ is the same as that at $670 \mathrm{~nm}$. However, absorption of light by aerosol particles will be taken into account. As a matter of course, number size distribution of aerosols at this wavelength is taken as that estimated at $670 \mathrm{~nm}$. Therefore, optical parameters to be estimated at 490nm are the imaginary part of complex refractive index and optical thickness of aerosols.

We generated the look-up table, LUT4, of RAD, POL and PD for typical values of $\mathrm{Nr}, \mathrm{Ni}$, a, $\mathrm{t}(550), \mathrm{SZA}, \mathrm{VZA}$ and RAZ in the same way as the case at $670 \mathrm{~nm}$. Then, the values of POL and PD for SZA, VZA, RAZ and Nr, a estimated at $670 \mathrm{~nm}$ were interpolated from LUT4 and were saved in a new file, nLUT4.

We use the nLUT4 file to estimate aerosol properties, Ni and $t(550)$, and the surface reflectance, A in the same way as described at (1) and (2) in the section 3.2.1. 


\subsubsection{Results}

The method described in the previous section was applied to PARASOL/POLDER data (P3L1TBG1032192JD) taken on April 28, 2006. Figure 6 shows the POLDER image over Japan (B: 490nm, G: 865nm, R: 670nm). We estimated the values of t, Nr, Ni, a and A at two target pixels including the symbol + shown in Figure 6.

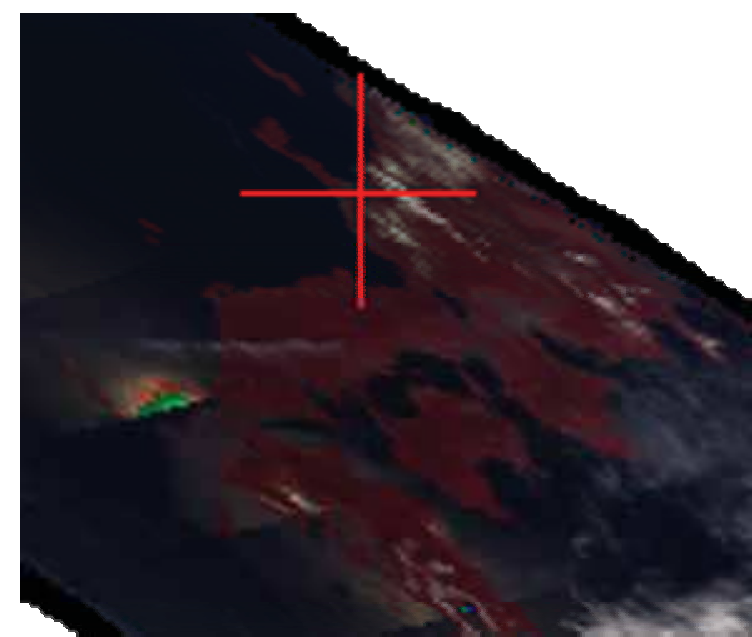

Fig. 6. Parasol/POLDER image over Japan taken on April 28,2006

\begin{tabular}{|c|ccccc||ccccc|}
\hline \multicolumn{5}{|c||}{$670 \mathrm{~nm}$} & \multicolumn{5}{c|}{$490 \mathrm{~nm}$} \\
\hline \hline Point & $\mathrm{Nr}$ & $\mathrm{Ni}$ & $\mathrm{a}$ & $\mathrm{t}(550)$ & $\mathrm{A}$ & $\mathrm{Nr}$ & $\mathrm{Ni}$ & $\mathrm{a}$ & $\mathrm{t}(550)$ & $\mathrm{A}$ \\
\hline 1 & 1.35 & 0 & 3.92 & 0.591 & 0.037 & 1.35 & 0.0066 & 3.92 & 0.607 & 0.1 \\
2 & 1.35 & 0 & 3.87 & 0.6 & 0.041 & 1.35 & 0.0057 & 3.87 & 0.6 & 0.1 \\
\hline
\end{tabular}

Table 1. Estimation results of aerosol properties and surface reflectances

In the estimation process of 3 parameters at $670 \mathrm{~nm}$, we chose POLDER data observed in viewing conditions in which the polarized radiances normalized by $\cos (\theta \mathrm{s}) \mathrm{E} / \Pi$ are larger than 0.02 . The results are shown in Table 1. The ground surface at two pixel points selected for the estimation of parameters represents urban and suburban areas. We can see from Table 1 that we have reasonable estimation values for the optical thickness of aerosols and surface reflectance. The polarized radiance and the apparent radiance computed by using parameters at $670 \mathrm{~nm}$ estimated at the point 1 in Table 1 and those received by the POLDER are shown in Figure 7, and Figure 8 shows the estimated radiance at the top of atmosphere and the observed ones at $670 \mathrm{~nm}$. The estimated polarized radiance and observed one at 490nm are shown in Figure 9 and the computed apparent radiance and observed one at $490 \mathrm{~nm}$ are shown in Figure 10. The radiance and polarized radiance shown in Figures 7 to 10 are normalized by $\cos (\theta \mathrm{s}) \mathrm{E} / \Pi$. As seen from Figures 7 to 10 , we have a good correspondence between the estimated values and observed ones. 


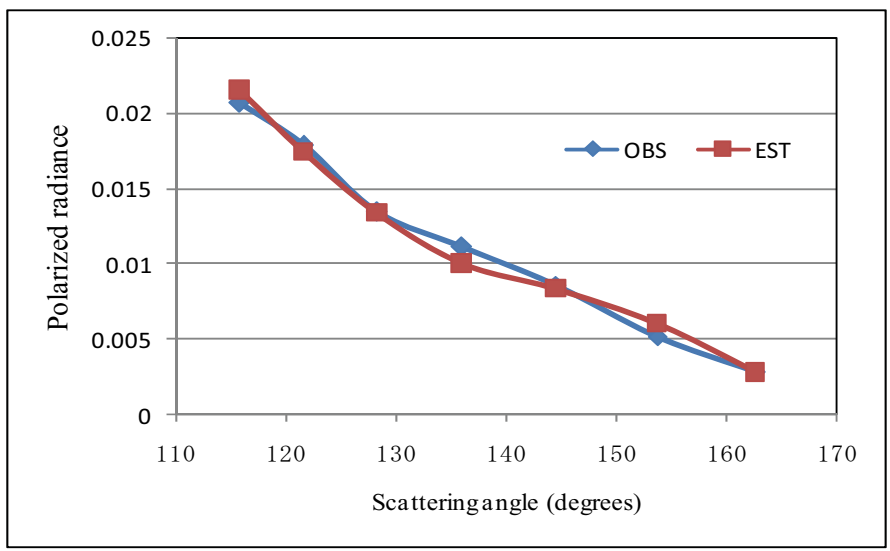

Fig. 7. The estimaded polarized radiances (EST) and observed ones (OBS) by the POLDER at $670 \mathrm{~nm}$

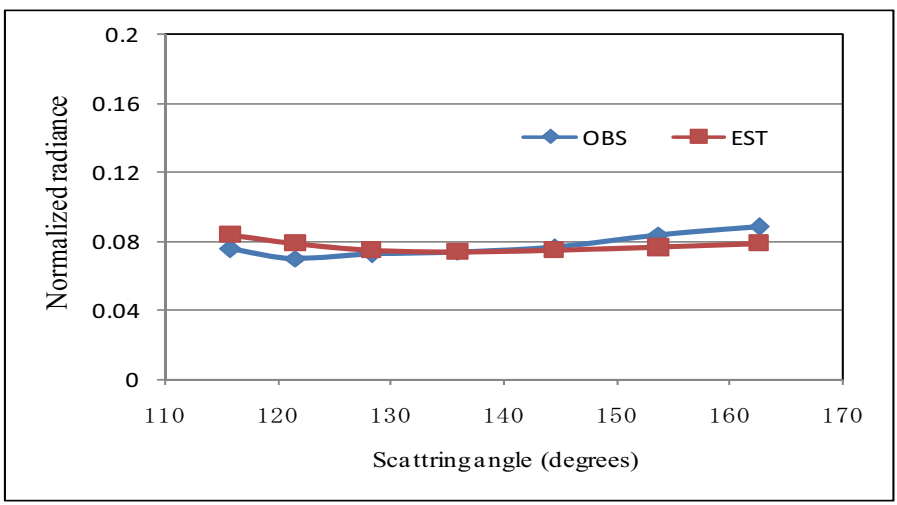

Fig. 8. The estimated radiances (EST) and observed ones (OBS) by the POLDER at $670 \mathrm{~nm}$.

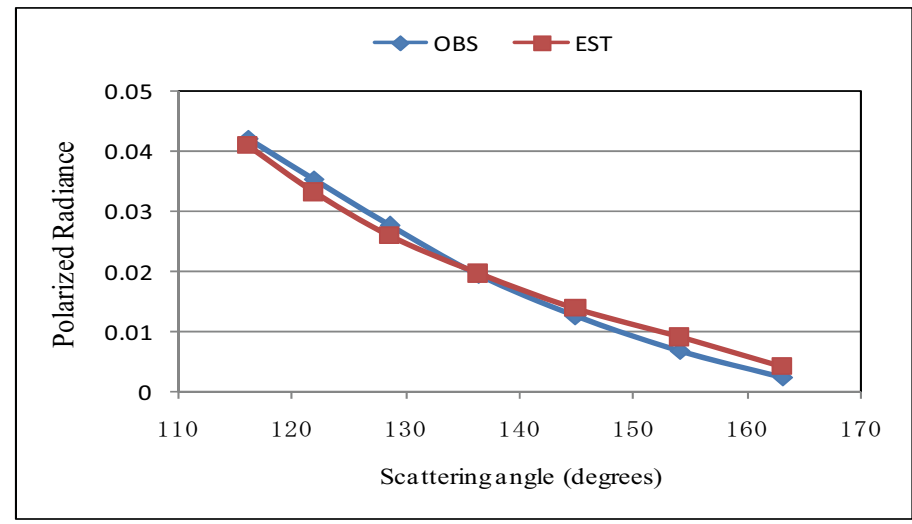

Fig. 9. The estimated polarized radiances (EST) and observed ones (OBS) at 490nm 


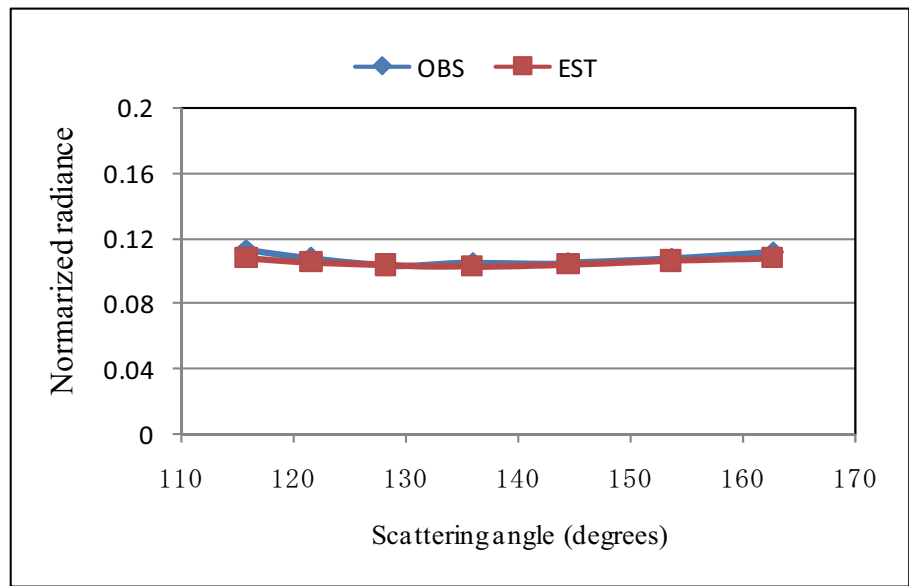

Fig. 10. The estimated radiances (EST) and observed ones by the POLDER at 490nm

\section{Conclusions}

Ground-based polarization measurements of the sky radiation were made at the Kanazawa city, Japan. The following results were obtained.

(1)Degrees of polarization measured in the sky covered with Asian dust are lower than those measured in the clear sky and decrease uniformly as the wavelength increases.

(2)The wavelength dependency of polarization is slightly different in the measurement date. In particular, most of degrees of polarization measured in the clear sky show the peak value around the $490 \mathrm{~nm}$ channel.

We also described the method for estimating optical properties of atmospheric aerosols including Asian dust and surface reflectances simultaneously from satellite and groundbased polarization data measured at multi-viewing angles. In addition to it, a new method for the estimation of aerosol properties over land using the polarized radiance measured by the POLDER effectively was proposed. As a result, it was shown that the method described in the present study provides reasonable values for aerosol properties and surface reflectances if it is assumed that the ground surface is the Lambertian diffuse reflector.

\section{References}

Hansen, J.E. and L.D. Travis (1974). Light scattering in planetary atmospheres, Space Science Reviews, vol.16, pp.527-610.

Hsu, N.C, S-C. Tsay, M.D.King and J.R.Herman, (2004). Aerosol properties over brightreflecting source regions, IEEE trans. Geosci. Remote Sensing, vol.42, pp.557-569

Ishimoto, H. and K. Masuda (2002). A Monte Carlo approach for the calculation of polarized light: application to an incident narrow beam, J. Quant. Spectrosc. Radiat. Transfer, Vol.72, pp.467-483

Kaufman, Y.J, D.Tanre, L.A.Remer, E.F.Vermote, D.A.Chu and B.A.Holben, (1997a). Remote sensing of tropospheric aerosol from EOS-MODIS over the land using dark targets and dynamic aerosol models, J. Geophys. Res., vol.17051-17067 
Kaufman,Y.J, A.Walt, L.A.Remer, B.C.Gao, R.R.Li and L.Flynn, (1997b). Remote sensing of aerosol over the continents with the aid of a $2.2 \mu \mathrm{m}$ channel, IEEE trans. Geosci. Remote Sensing, vol.35, pp.1286-1298

Kusaka, T, S. Mori, T. Suzuki and H. Shibata (2001). Estimation of optical parameters of yellow sand dust clouds over desert areas from Satellite_level data, IEEE Proc. IGARSS2001, CD-ROM

Kusaka, T, F. Satou and Y. Hayato (2002a). Optical properties of Kosa aerosols estimated from the multi-spectral polarization, Proc of Remote Sensing Asia'02 Symposium, SPIE, CD-ROM.

Kusaka, T, S.Mori and T.Yobuko, (2002b). Estimation of optical parameters of sand dust Clouds and ground Reflectance from satellite data, IEEE proc. of IGARSS2002, CDROM

Kusaka, T and T.Nishisaka, (2004). Simultaneous estimation of optical parameters of the Asian dust and ground reflectance from POLDER data, Proc. of SPIE Vol.5652

Kusaka, T and H. Kitaguchi, (2007), Evaluation of optical properties of atmospheric aerosols estimated from ground-based polarization measurements, IEEE Proc.of IGARSS2007, Barcelona, Spain, CD-ROM

Masuda, K and M. Sasaki, (1997). A multi-spectral polarimeter for measurements of direct solar and diffuse sky radiation: Calibration and measurements, Optical Review, Vol.4, pp.496-501

Nakajima, T and A. Higurashi, (1998). A use of two-channel radiance for an aerosol characterrization from space, Geophys. Res. Lett. vol.25, pp.3815-3818, 1998

NASA, AERONET(AErosol RObotic NETwork), http:/ /aeronet.gsfc.nasa.gov/

NIES, National Institute for Environmental Studies, Japan, http:/ / www-lidar.nies.go.jp/

O'Brien,D.M. (1998). Monte Carlo integration of the radiative transfer equation in a scattering medium with stochastic reflecting boundary, J. Quant. Spectrosc. Radiat. Transfer, vol.60, pp.573-583

Tanre, D and M.Legrand, (1991). On the satellite retrieval of Saharan dust optical thickness over land: Two different approaches, J. Geophys. Res.,vol.96, pp.5221-5227

Tanre,D, Y.J.Kaufman, M.Herman and S.Mattoo, (1997). Remote sensing of aerosol over oceans from EOS-MODIS, J. Geophys. Res., vol.102, pp.16971-16988

Vermote E., D. Tanre, J. L. Deuze, M. Herman, J. J. Morcrette, and S. Y. Kotchenova, (2006). $6 \mathrm{~S}$ user guide ver.3 in Second simulation of a satellite signal in the solar spectrum vector $(6 \mathrm{SV})$ 


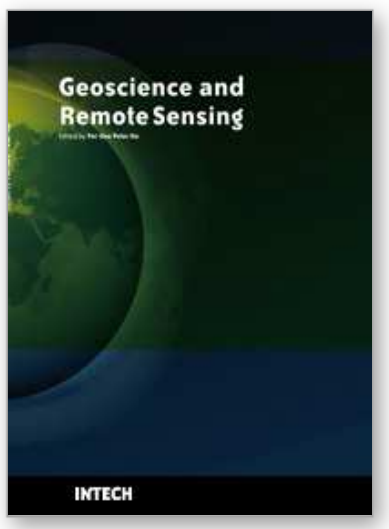

\author{
Geoscience and Remote Sensing
}

Edited by Pei-Gee Peter Ho

ISBN 978-953-307-003-2

Hard cover, 598 pages

Publisher InTech

Published online 01, October, 2009

Published in print edition October, 2009

Remote Sensing is collecting and interpreting information on targets without being in physical contact with the objects. Aircraft, satellites ...etc are the major platforms for remote sensing observations. Unlike electrical, magnetic and gravity surveys that measure force fields, remote sensing technology is commonly referred to methods that employ electromagnetic energy as radio waves, light and heat as the means of detecting and measuring target characteristics. Geoscience is a study of nature world from the core of the earth, to the depths of oceans and to the outer space. This branch of study can help mitigate volcanic eruptions, floods, landslides ... etc terrible human life disaster and help develop ground water, mineral ores, fossil fuels and construction materials. Also, it studies physical, chemical reactions to understand the distribution of the nature resources. Therefore, the geoscience encompass earth, atmospheric, oceanography, pedology, petrology, mineralogy, hydrology and geology. This book covers latest and futuristic developments in remote sensing novel theory and applications by numerous scholars, researchers and experts. It is organized into 26 excellent chapters which include optical and infrared modeling, microwave scattering propagation, forests and vegetation, soils, ocean temperature, geographic information, object classification, data mining, image processing, passive optical sensor, multispectral and hyperspectral sensing, lidar, radiometer instruments, calibration, active microwave and SAR processing. Last but not the least, this book presented chapters that highlight frontier works in remote sensing information processing. I am very pleased to have leaders in the field to prepare and contribute their most current research and development work. Although no attempt is made to cover every topic in remote sensing and geoscience, these entire 26 remote sensing technology chapters shall give readers a good insight. All topics listed are equal important and significant.

\title{
How to reference
}

In order to correctly reference this scholarly work, feel free to copy and paste the following:

Takashi Kusaka and Ryuichi Taniguchi (2009). Simultaneous Estimation of Optical Properties of Asian Dust and Ground Reflectance by Polarization Measurements, Geoscience and Remote Sensing, Pei-Gee Peter Ho (Ed.), ISBN: 978-953-307-003-2, InTech, Available from: http://www.intechopen.com/books/geoscience-andremote-sensing/simultaneous-estimation-of-optical-properties-of-asian-dust-and-ground-reflectance-bypolarization-m

\section{INTECH}

open science | open minds

\section{InTech Europe}

University Campus STeP Ri

\section{InTech China}

Unit 405, Office Block, Hotel Equatorial Shanghai 
Slavka Krautzeka 83/A

51000 Rijeka, Croatia

Phone: +385 (51) 770447

Fax: +385 (51) 686166

www.intechopen.com
No.65, Yan An Road (West), Shanghai, 200040, China 中国上海市延安西路65号上海国际贵都大饭店办公楼405单元 Phone: +86-21-62489820

Fax: +86-21-62489821 
(C) 2009 The Author(s). Licensee IntechOpen. This chapter is distributed under the terms of the Creative Commons Attribution-NonCommercial-ShareAlike-3.0 License, which permits use, distribution and reproduction for non-commercial purposes, provided the original is properly cited and derivative works building on this content are distributed under the same license. 